\title{
Drivers of Collaboration in Political Decision Making: A Cross-Sector Perspective
}

\author{
Manuel Fischer, Eawag and University of Berne \\ Pascal Sciarini, University of Geneva
}

Collaboration between actors in political decision-making processes is crucial from both an actor and a process perspective. Previous studies have highlighted the role of preference similarity, power, and opportunity structures as drivers of collaboration. However, these studies have focused on single policy sectors and have therefore overlooked possible differences in effects across sectors, as well as interactions between sectors. This article innovates by taking a cross-sector perspective. Applying exponential random graph models to collaboration networks covering 11 decisionmaking processes, we show that relational opportunity structures have a fairly consistent influence on collaboration, whereas the effects of social and institutional opportunity structures vary across processes. The effect of institutional opportunity structures is contingent on the importance of institutional arenas. Our hypothesis on cross-sector influences receives partial support. Opportunity structures and interactions between sectors add to preference similarity and power, which have a strong and robust influence on collaborative tie formation.

$\mathrm{P}$ olitical actors such as interest groups, parties, or administrative agencies collaborate during decision-making processes in order to translate their goals into policy. From an actor-level perspective, collaboration with other actors is crucial. It helps to exchange information regarding the issue at stake, to gain access to resources, to form coalitions, and, ultimately, to influence policy outputs. From the perspective of a political decision-making process, collaboration favors the emergence of trust among actors (Berardo 2009; Lubell 2007) and is beneficial to effective compromise seeking and problem solving in governance networks (Schneider et al. 2003). Given the central role that collaboration between political actors plays, it is of utmost importance to understand the factors that drive collaboration.

Earlier studies have shown that preference similarity, functional interdependence, or perceived power is an important predictor of collaboration (e.g., Gerber, Henry, and Lubell 2013; König and Bräuninger 1998; Zafonte and Sa- batier 1998). Leifeld and Schneider (2012) have added institutional, social, and relational opportunity structures to the list. Collaboration not only is beneficial to actors but also implies transaction costs (Lubell et al. 2002). Opportunity structures help actors to choose contacts that minimize transaction costs while maximizing outreach.

Yet, existing studies of collaboration between political actors suffer from a shortcoming: they usually focus on single policy sectors, such as toxic chemicals control (Leifeld and Schneider 2012), water management (Berardo 2013; Schneider et al. 2003; Zafonte and Sabatier 1998), labor policy (König and Bräuninger 1998), or regional planning (Gerber et al. 2013). Therefore, they are likely to overlook two important elements. First, it is acknowledged that the patterns of collaboration vary across policy sectors, depending on the characteristics of these sectors (Weible 2005, 473). Focusing on a single policy sector prevents the identification of possible differences in the drivers of collaboration from one sector to another. To be confident in the validity of

Manuel Fischer (manuel.fischer@eawag.ch) is a researcher at the Department of Environmental Social Sciences at the Swiss Institute for Aquatic Science and Technology (Eawag), Dübendorf, Switzerland, and a lecturer at the Institute of Political Science at the University of Berne, Switzerland. Pascal Sciarini (pascal.sciarini@unige.ch) is a professor of Swiss and comparative politics at the Department of Political Science and International Relations at the University of Geneva, Switzerland.

Data and supporting materials necessary to reproduce the numerical results in the article are available in the JOP Dataverse (https://ataverse.harvard.edu /dataverse/jop). An online appendix with supplementary material is available at http://dx.doi.org/10.1086/683061.

The Journal of Politics, volume 78, number 1. Published online September 8, 2015. http://dx.doi.org/10.1086/683061

(C) 2015 by the Southern Political Science Association. All rights reserved. 0022-3816/2016/7801-0005\$10.00 
earlier findings, one must check their robustness throughout a variety of sectors (Henry 2011, 367; Weible and Sabatier 2005, 195). Second, sector-specific studies fail to take into account possible interactions across sectors. Interactions between policy sectors can be important but are most often ignored in the literature (Hoberg and Morawski 2008; Jones and Jenkins-Smith 2009).

This article takes a comparative perspective across policy sectors. We make three contributions. First, we put the findings of earlier studies regarding opportunity structures and other drivers of collaboration to a more challenging test. Second, we examine whether the effects of institutional opportunity structures on collaborative tie formation vary depending on process-related characteristics. Third, we innovate by looking at interactions across sectors. In a political system, many decision-making processes develop in parallel and contemporaneously, actors have multiplex relations, and the creation of collaborative ties in a policy sector is likely influenced by collaboration established in other sectors (Shrestha, Berardo, and Feiock 2014; Shrestha and Feiock 2009).

Because political actors collaborate with several other actors at the same time, we adopt a network perspective. Our empirical tests are based on a unique data set of collaboration networks covering the 11 most important decisionmaking processes in Switzerland in the early 2000s. Network data on multiple policy sectors are rare in political science (Lubell, Henry, and McCoy 2010; Lubell et al. 2012; Scholz, Berardo, and Kile 2008, 397). Our data were gathered through interviews with representatives of 251 collective political actors participating in these 11 processes, which each corresponds to a specific policy sector. ${ }^{1}$ To analyze the data, we run exponential random graph models (ERGMs). Unlike standard regression models, ERGMs are able to take into account the specific dependence structure of network data.

In the theoretical section, we first discuss the importance of collaboration for political decision making in general and for political actors in particular. We then review the various drivers of collaboration. On the basis of that, we develop our argument regarding the likely differences between processes and the role of interactions across processes. The next section presents the data, the method, and the model and

1. In the existing literature the terms policy sector, policy domain, and policy subsystem are all used to describe a set of related policy issues and actors that engage in politics around these issues (e.g., Sabatier and Weible 2007). In this article, we use the term policy sector. In addition, given that our empirical material stems from 11 decision-making processes corresponding each to a specific policy sector, we use "processes" and "sectors" interchangeably. sets the stage for empirical tests. In conclusion, we highlight the broader implications of our findings.

\section{COLLABORATION AMONG POLITICAL ACTORS}

On the level of political decision-making processes, collaboration among actors encourages the emergence of trust, facilitates coordination and communication, reduces incentives for opportunism, and helps actors to overcome collective action dilemmas (e.g., Feiock and Scholz 2010; Lubell et al. 2002; Putnam 1995; Sabatier 1987; Schneider et al. 2003). Identifying the factors that drive collaboration is thus crucial if one wishes to understand how political decision making works - and how well it performs. On the level of single collective political actors, such as political parties, interest groups, or administrative offices, collaboration with others helps them to translate their goals into policy. In modern political systems, technical, financial, and political resources are fragmented, and no actor alone has enough resources to unilaterally influence political decision making (Schneider et al. 2003). Collaboration with other actors is therefore necessary if actors want to influence policy outputs (Berardo and Scholz 2010; Henry 2011).

Yet, establishing collaboration causes transaction costs (Lubell et al. 2002; North 1990). Contacting other actors and keeping up collaboration require time and resources. Time and resources spent on collaboration with one actor cannot be used for contacting another actor or for any other activity. Given these transaction costs, political actors cannot afford to collaborate with all other potentially relevant actors but have to weigh the costs and benefits of establishing collaborative ties (Feiock et al. 2010; Feiock and Scholz 2010; Leifeld and Schneider 2012; Lubell et al. 2002; Schneider et al. 2003). This trade-off might prevent political actors from taking coordinated policy decisions and from dealing with collective action problems (Berardo and Scholz 2010; Feiock and Scholz 2010).

Preference similarity, perceived power, and formal authority are the usual criteria that political actors may rely on when deciding to establish collaborative contacts. First, to increase their benefits and achieve their policy goals, political actors tend to collaborate with others with which they share policy preferences (e.g., Henry 2011; Sabatier 1987; Weible and Sabatier 2005; Zafonte and Sabatier 1998). Second, actors in search of information or allies tend to collaborate with alters they see as powerful, since such contacts appear as most promising in terms of influence (Henry 2011; Leifeld and Schneider 2012; Stokman and Zeggelink 1996). Third, for the same reason, actors also tend to collaborate with partners such as state actors, which have formal authority over a decision-making process (König and Bräuninger 1998). 


\section{Opportunity structures as drivers of collaboration and differences between sectors}

To the same extent that actors attempt to increase their benefits by creating collaborative ties with powerful partners or with partners with similar preferences, they may also use opportunity structures to evaluate the costs and benefits of a new contact (Leifeld and Schneider 2012; Schneider et al. 2003). Opportunity structures have been used in the literature on network management (e.g., Klijn, Steijn, and Edelenbos 2010), policy networks (Laumann and Pappi 1973), or public policy (e.g., "coalition opportunity structures"; Fischer 2015; Sabatier and Weible 2007). In line with Leifeld and Schneider (2012), we conceive of opportunity structures as either preexisting collaboration ties or institutional arenas that actors may use to lower transaction and informational costs and increase their confidence that establishing a contact is worth the effort. More specifically, we look at three distinct forms of opportunity structures.

First, relational opportunity structures stem from preexisting communication channels between two actors that favor the creation of additional ties between those actors (Feiock and Scholz 2010; Granovetter 1985; Leifeld and Schneider 2012; Putnam 1995). More specifically, if an actor $a$ sends information to actor $b$, then actor $b$ is likely to reciprocate the tie and also send information to actor $a$. Reciprocation, or the establishment of "bonding relations" (Berardo and Scholz 2010), decreases the risk of defection of the collaboration partner and provides a mutual deterrence on which trust and credible commitments can develop (Berardo 2009; Feiock et al. 2010; Shrestha and Feiock 2011).

Second, social opportunity structures refer to the existence of actors' shared collaboration partners, which also facilitates collaboration (Berardo and Scholz 2010; Carpenter, Esterling, and Lazer 2004; Feiock and Scholz 2010; Leifeld and Schneider 2012). Actors prefer to collaborate with those they already know indirectly (Granovetter 1985). More specifically, relying on contacts of collaboration partners lowers the costs of new contacts and increases confidence that these collaboration efforts will be rewarding. In addition, shared contacts act as a sort of social control by increasing the costs of defection (Feiock et al. 2010). In other words, organizational actors, as individuals, use common "friends" to reduce the uncertainty about the quality and trustfulness of a new contact. Thus, if a political party $a$ and an interest group $i$ collaborate, it is likely that another political party $b$ that collaborates with party $a$ will also collaborate with interest group $i$.

Finally, institutional opportunity structures refer to the opportunity granted to collective actors that meet in institutional arenas of a decision-making process to develop collaboration (Leifeld and Schneider 2012; Lubell et al. 2002; Sabatier and Weible 2007; Williamson 1991). Joint participation in institutional arenas such as consultation procedures and shared membership in working groups or policy committees reduce transaction costs. First, joint participation facilitates communication and the development of mutual knowledge and trust between actors. The higher the number of institutional arenas in which two actors meet, the more they have a chance to learn about each other, to develop mutual trust, and to form collaborative ties. Second, actors' exchanges in arenas dealing with specific political issues provide them with a thematic frame to develop collaboration.

From these arguments we derive our first hypothesis regarding the role of opportunity structures as collaboration drivers.

H1. Social, relational, and institutional opportunity structures increase the likelihood of collaboration between actors.

\section{Differences in drivers of collaboration across decision-making processes}

Going one step further, we argue that drivers of collaboration do not exert their effects in all policy sectors or decisionmaking processes to the same extent. Instead, we assume that the effects of some drivers vary depending on the characteristics of these sectors or processes (Henry 2011, 367; Weible and Sabatier 2005, 195). On the one hand, factors such as actors' power or preference similarity are likely to foster collaboration in any case, regardless of sector- or processrelated characteristics. Similarly, social or relational opportunity structures tackle endogenous network effects that are unlikely to vary across political decision-making processes. On the other hand, the influence of institutional opportunity structures is presumably less systematic and more sensitive to process-related factors. Institutional opportunity structures are defined by elements external to the collaboration network itself, that is, by the institutional design of a decision-making process. This, in turn, may condition their influence on collaborative tie formation.

More concretely, we argue that the influence of joint participation in institutional arenas on the likelihood of collaboration depends on the importance of these arenas, that is, on the extent to which they contribute to the output of the decision-making process. While some institutional arenas mostly serve for information provision and actor consultation ("all talk, no action"; see Lubell 2004), others allow for negotiation, coproduction of solutions, and codecision (Verweij et al. 2013). These differences affect actors' payoffs of partic- 
ipation (Feiock 2013; Jenkins-Smith et al. 2014; Koontz and Johnson 2004). Actors are expected to invest more resources, time, and collaboration efforts in arenas where policy outputs are negotiated and coproduced than in simple consultation arenas. Two actors meeting in an arena of little importance for the policy outputs will have little incentives to create collaborative ties. By contrast, meeting in an arena in which important decisions are made will prompt actors to use the opportunity and to establish collaboration.

H2. The influence of institutional opportunity structures on collaborative tie formation depends on the importance of the corresponding institutional arenas: the higher that importance, the higher the influence of institutional opportunity structures.

\section{Interactions between decision-making processes}

The increasing complexity of policy problems has led to the growing specialization of political actors and to a strong functional differentiation of public policies along sectoral lines. Accordingly, important theories of the policy process, such as the advocacy coalition framework (Sabatier 1987) or the punctuated equilibrium theory (Baumgartner and Jones 1991), typically focus on single policy sectors. Yet scholars are increasingly aware that considering policy sectors in isolation from one another has strong limitations, as many political actors are active in several policy sectors at the same time. Therefore, they have started to study interactions between multiple sectors.

With respect to policy outputs, there is compelling evidence of policy learning, diffusion, and spillover mechanisms between sectors (e.g., Gilardi 2010; Jones and JenkinsSmith 2009). Interactions between sectors do not only regard policy outputs but also hold for political bargaining and decision making. Zafonte and Sabatier (1998) argue that actors in overlapping and nested subsystems are functionally interdependent. Interdependence, in turn, increases the need for mutual coordination. Jones and Jenkins-Smith (2009) point to the importance of policy entrepreneurs linking previously unconnected issues. Lubell et al.'s (2010) concept of the ecology of games emphasizes that actors are simultaneously negotiating issues in different, parallel institutional arenas, which in turn influences their strategic behavior. Finally, authors argue that coalition building in one sector is influenced by existing coalitions in other sectors (Hoberg and Morawski 2008; Lubell et al. 2012).

In light of these arguments, focusing the analysis of collaboration on a single policy sector and neglecting the role played by existing collaborative ties in other sectors appears as a major weakness. To provide a more comprehensive view of the determinants of collaboration, one needs to take into account interactions between sectors. Actors are connected through a multiplexity of collaborative ties across sectors, and these ties are likely to influence each other (Heaney 2014; Shrestha et al. 2014; Shrestha and Feiock 2009). Such a situation can be seen as a series of multiple games, in which the payoffs in each individual game also affect the payoff in the other game (Shrestha and Feiock 2009). First, parallel collaboration in a variety of sectors creates opportunities for communication and the development of mutual trust and control (Coleman 1988; Putnam 1995), which increases the odds that actors also collaborate in the policy sector of interest. Second, not collaborating with an actor with which one is already connected in other policy sectors is risky, since this may endanger collaboration in these other sectors, too. ${ }^{2}$

H3. The more actors collaborate in other, parallel decision-making processes, the more they are likely to collaborate in the decision-making process of interest.

\section{DATA, METHOD, AND MODELS}

Comparable network data on several decision-making processes are rare, and gathering such data is costly and timeconsuming. In that sense, our data set is fairly unique: It includes collaboration network data regarding the 11 most important political decision-making processes of the years 2001-6 in Switzerland. These processes, which we selected on the basis of a survey among 80 experts of Swiss politics, constitute the eleventh pension reform, the program of budget relief 2003, the extension of the bilateral agreement with the European Union on the free movement of persons, the bilateral agreement with the European Union on the taxation of savings, the bilateral agreement with the European Union on Schengen/Dublin, the law on nuclear energy, the law on the infrastructure fund, the new law on foreigners, the reform of fiscal equalization and tasks distribution between the federal state and cantons, the new constitutional article on education, and the telecommunications act.

To identify the main actors involved in each decisionmaking process, we used the classical combination of positional, decisional, and reputational approaches (see, e.g.,

2. Like Shrestha and Feiock (2009), we will be unable to determine whether trust or mutual control ultimately causes the cross-sector dependencies. 


\begin{tabular}{|c|c|c|c|c|c|c|c|}
\hline Process & $\begin{array}{c}\text { Duration of } \\
\text { Process }\end{array}$ & $\begin{array}{l}\text { Number } \\
\text { of Actors }\end{array}$ & $\begin{array}{c}\text { Density of } \\
\text { Collaboration } \\
\text { Network }\end{array}$ & $\begin{array}{c}\text { Average } \\
\text { Number of } \\
\text { Ties per Actor }\end{array}$ & $\begin{array}{c}\text { Share of } \\
\text { Reciprocated } \\
\text { Ties }\end{array}$ & $\begin{array}{c}\text { Average } \\
\text { Number of } \\
\text { Collaboration } \\
\text { Ties in Parallel } \\
\text { Processes }\end{array}$ & $\begin{array}{c}\text { Importance of } \\
\text { the Preparatory } \\
\text { Phase }\end{array}$ \\
\hline Education & 1997-2006 & 20 & .41 & 7.9 & .49 & 1.15 & .73 \\
\hline Infrastructure & $2001-7$ & 22 & .38 & 8.1 & .35 & .51 & .67 \\
\hline Fiscal equalization & $1991-2004$ & 24 & .28 & 6.5 & .35 & .81 & .64 \\
\hline Budget relief & $2002-4$ & 25 & .30 & 7.2 & .47 & .78 & .63 \\
\hline Nuclear & $1998-2003$ & 24 & .28 & 6.5 & .44 & .51 & .60 \\
\hline Pensions & 1995-2004 & 23 & .31 & 6.9 & .46 & .84 & .60 \\
\hline Savings & $2000-2005$ & 19 & .30 & 5.5 & .46 & 1.12 & .56 \\
\hline Foreigners & 1995-2006 & 20 & .27 & 5.2 & .25 & 1.02 & .55 \\
\hline Telecom & $2000-2006$ & 22 & .43 & 9.0 & .42 & .39 & .47 \\
\hline Persons & $2002-5$ & 26 & .33 & 8.2 & .55 & .81 & .47 \\
\hline Schengen & 2000-2005 & 26 & .33 & 8.2 & .37 & .61 & .44 \\
\hline Average & 7.7 years & 22.8 & .33 & 7.2 & .42 & .78 & .58 \\
\hline
\end{tabular}

Knoke 1993, 30). ${ }^{3}$ This ensures comparability of actor selection across cases and with earlier work. This delineation does admittedly not include every single actor participating in each policy process but concentrates on the main actors, that is, the ones that were able to influence the policy output. Data on the collaboration network regarding each of the 11 decision-making processes were gathered through 251 semistructured face-to-face interviews - a minimum of 19 for the process on the taxation of savings and a maximum of 26 for the processes on the free movement of persons and the Schengen/Dublin agreement-with representatives of the main collective actors (political parties, interest groups, government and administrative agencies, etc.) participating in the processes. ${ }^{4}$ Table 1 shows descriptive statistics on the 11 processes.

\section{Exponential random graph models (ERGM)}

To evaluate the impact of opportunity structures - and other relevant variables - on collaborative tie formation, we

3. Following the decisional approach, we identified the actors that took part in the different arenas (e.g., policy committees, consultation procedure, parliamentary committees, etc.) of a given decision-making process. To this list, we added the actors holding a strategic position in the Swiss political system (positional approach). Finally, we checked during the first interviews conducted with the senior civil servants responsible for the decision-making process that no powerful actor was missing (reputational approach).

4. Only actors that participated in at least one other venue in addition to the very open consultation procedure were interviewed. Most of the interviews were conducted between February and July 2008. estimate exponential random graph models (ERGM; Robins et al. 2007). ERGMs are explicitly designed for statistical inference on network data (for applications in political science, see, e.g., Cranmer and Desmarais [2011]; Fischer and Sciarini [2015]; Gerber et al. [2013]; Leifeld and Schneider [2012]). Observations on network ties are by definition mutually dependent. The assumption that a collaboration tie between actors $i$ and $j$ is independent of any other collaboration ties that actors $i$ and $j$ have with other actors in the network is highly unrealistic. Instead, the probability of a collaboration tie between two actors at least partly depends on the structural properties of the network in which the two actors are embedded. Standard regression models are unable to take this dependency into account and would erroneously attribute explanatory power to other independent variables, instead of attributing them to endogenous network structures (Cranmer and Desmarais 2011). In other words, with simple ordinary least squares regression, the error terms would be correlated across observations, standard errors would be too small, and $p$-values for exogenous variables would be too optimistic (Leifeld and Schneider 2012).

In order to construct a model without assuming relational independence, the dependent variable of an ERGM is the whole network as one single observation (Cranmer and Desmarais 2011). The structure of the whole network is modeled as a function of actor-level variables (node covariates), dyadic variables (edge covariates), and endogenous network structures. Endogenous network structures refer to effects of network structures on the network itself, like actors' tendency to reciprocate ties or close triangles (i.e., to 
collaborate with an actor to which one is already indirectly connected). The relationship between the probability of a network $m$ and the network statistics in $\Gamma$ can be expressed by the following formula, where $\theta$ is the vector of $k$ parameters that describe the dependence of $P\left(Y_{m}\right)$ on the network statistics in $\Gamma$ (Cranmer and Desmarais 2011; Hunter et al. 2008):

$$
P\left(Y_{m}\right)=\frac{\exp \left(-\sum_{j=1}^{k} \Gamma_{m j} \Theta_{j}\right)}{\sum_{m=1}^{k} \exp \left(-\sum_{j=1}^{k} \Gamma_{m j} \Theta_{j}\right)} .
$$

As represented by the formula, ERGMs calculate the probability of observing the given network over all the networks that could have been observed. Expressed as in the formula above, the ERGM has an exponential family form log likelihood function. However, given the very high number of possible network configurations, computing the exact maximum likelihood is too demanding (Cranmer and Desmarais 2011). Therefore, models are estimated using Markov chain Monte Carlo maximum likelihood (MCMC-MLE), which approximates the exact likelihood by relying on a sample from the range of possible networks to estimate the parameters (Cranmer and Desmarais 2011). ${ }^{5}$ The iterative optimization of the MCMC algorithm proceeds until there is little change in the approximate likelihood function value, that is, when the differences between the coefficients in the observed network and the average coefficients in the sample of simulated networks are no longer significant $(p>.05$; Cranmer and Desmarais 2011). Model fit is also assessed by comparing the observed network to simulated networks. ${ }^{6}$

5. The MCMC algorithm proceeds as follows: in a given optimization iteration, the sum in the denominator of the likelihood function is approximated using a series of networks sampled from the distribution parameterized with those parameters that maximized the likelihood using the previous sample of networks.

6. Technically, the comparison is based on a set of network statistics not included in the model: $p$-values are used to check whether the observed network statistics are not different from the simulated network statistics. A common threshold used for assessing model fit is a $p$-value $>.05$ (Hunter, Goodreau, and Handcock 2008). The goodness of fit (GOF) values reported below (GOF indegree, GOF outdegree, GOF edgewise, GOF geodesic) indicate the percentage of observed network statistics (e.g., number of nodes with indegree 1 , with indegree 2 , with indegree 3 , and so on) successfully simulated by the model for each of the four network statistics. Usually, $p$-values are indicated for each observed network statistic for the four types of endogenous structures (Hunter, Goodreau, and Handcock 2008). For space reasons, we indicate only the percentage of successfully ( $p$-value $>.05$ ) simulated network statistics for each of the four types of statistics. Most models are able to simulate more than $85 \%$ of all statistics correctly, and, on average, the complete model including collaboration in parallel networks fits the data better than the alternative model excluding it (see model A2 in the appendix, available online). Detailed GOF figures for each single statistic are available from the authors on request.

\section{The outcome network: Collaboration among collective actors}

The outcome network comprises the directed collaboration ties among the collective political actors involved in the respective decision-making processes. To identify the collaboration network among actors, we asked our interview partners to indicate, from a list of actors that participated in a given decision-making process, those actors with which they had collaborated intensely, that is, with which they had frequent contact without necessarily agreeing on the substantive policy issue at stake. ${ }^{7}$ Table 1 presents descriptive indicators of the outcome networks. The density of the 11 collaboration networks, as measured by the number of observed ties out of the total number of possible ties, ranges from 0.27 to $0.43{ }^{8}$

\section{Independent variables and controls}

We use actors' joint participation in arenas of the preparatory, preparliamentary phase of the decision-making process as an indicator of the institutional opportunity structure. We asked the interview partners to indicate in which institutional arenas their organization participated, from a list comprising all arenas of the preparatory phase of the decision-making process at stake (from 10 to 15 arenas per process). On the basis of this, we constructed networks of joint participation, where the strength of the tie between two actors (edge covariate) is measured by the number of institutional arenas both actors participated in.

Endogenous network effects, namely, reciprocity and transitivity, serve as indicators of relational and social opportunity structures, respectively (Leifeld and Schneider 2012). The reciprocity parameter informs about the actors' tendency to reciprocate ties. Reciprocity exists if actor $a$ indicates collaboration with actor $b$ and $b$ reciprocates this tie. Empirically, reciprocity in the collaboration networks varies from a minimum of $25 \%$ to a maximum of $55 \%$ (table 1). The GWESP (geometrically weighted edgewise shared partners) and GWDSP (geometrically weighted dyadwise shared partners) parameters measure transitive closure

7. Exact wording of the question: "Which actors did your organization strongly collaborate with during the decision-making process $x$ ?" Rationales for collaboration can be the exchange of information, advice, or resources; the coordination in a coalition; or the search for access to influential actors (Weible and Sabatier 2005, 182). Given the absence of agreement in the literature on the actual content of relationship that one should focus on (Scholz et al. 2008), we deliberately refrained from specifying this content and opted instead for a broad definition of collaboration.

8. The density of a network corresponds to the number of ties divided by the total number of possible ties. It ranges from 0 (empty network) to 1 . 
and should be interpreted together (Hunter 2007). The GWDSP captures the tendency of a dyad (i.e., of a pair of actors that are collaborating or not) to have one or more shared partners. It is a baseline effect that controls whether any two actors in the network tend to have shared partners. Once dyadwise shared partners have been controlled for, the GWESP measures whether two actors that collaborate are more likely than pure chance to have common partners (Leifeld and Schneider 2012). ${ }^{9}$

The variable (edge covariate) measuring collaboration in other processes, which serves to test our third hypothesis, is also based on the interview question used to construct the outcome networks. It counts the number of other decisionmaking processes in which two actors collaborate. It ranges from zero to 10 , but empirically actors have only $0.78 \mathrm{col}-$ laboration ties, on average, in other, parallel networks (table 1). ${ }^{10}$

Four additional, exogenous variables identified as drivers of collaboration in the existing literature are introduced as controls. First, our measure of preference similarity is again based on interview data. Actors were asked to select, from the same list of actors participating in the process mentioned above, those actors with which they had converging or diverging preferences about the policy project. ${ }^{11}$ This information is represented as a network whose ties express preference similarity (1) or preference dissimilarity $(-1)$ and is added to the model as an edge covariate term. Second, we include two control variables representing actors' power. One is reputational power (Fischer and Sciarini 2015), and it also stems from interview data: We asked our

9. GWESP and GWDSP include a geometric weighting parameter; i.e., the number of shared partners per dyad is weighted. A low geometrical weighting parameter of 0.1 for both parameters means that two actors are unlikely to have a lot of shared partners and avoids model degeneracy (Leifeld and Schneider 2012; Morris, Handcock, and Hunter 2008). Degeneracy results from the specification of a model that is so unlikely to have generated the observed network that the ERGM cannot be computed. In most of these cases, the Markov chain moves to an extreme graph, i.e., either a complete (fully connected) or empty (entirely unconnected) network, and stays there (Cranmer and Desmarais 2011).

10. Of course, for each decision-making process under study, collaboration in the other 10 decision-making processes captures only part of what is going on in parallel. However, given that our study includes the 11 most important decision-making processes of the early 2000s and covers a wide range of policy sectors, we can be confident that our variable "collaboration in other processes" is a reliable indicator of the broader relational structure. Further, table 1 shows that all processes do temporarily overlap, at least between 2002 and 2004.

11. Exact wording of the question: "With which actors did your organization have convergent or divergent preferences with respect to the decision-making process $x$ ?" interview partners to indicate which actors were-in their view - very influential in the respective decision-making process, again on the basis of the same list of actors. ${ }^{12}$ This results in a binary matrix of reputation attribution. In addition, we introduce a dummy variable measuring formal authority. The variable differentiates state actors from nonstate actors and relates to two effects in the models: state actors' outgoing and incoming ties (Ingold and Fischer 2014).

Third, our models control for the tendency of actors to collaborate with actors of the same type. Such phenomena of homophily are common in collaboration networks (Gerber et al. 2013; Scholz et al. 2008). We group actors in five actor types (state actors, political parties, interest groups, cantons, and others) and include this variable as a node covariate. The fourth control variable distinguishes the actors that participated in many decision-making processes (the so-called "generalists") from those that participated in very few processes (the "specialists"). It is included as a node covariate and ranges from one to 11 . We need this control variable in order to test accurately the effect of collaboration in other policy processes. Obviously, the number of other decision-making processes in which two actors collaborate is likely to be higher among actors that participate in several processes than among actors that participate in a small number of processes only.

Regarding finally process-level characteristics, for reasons of consistency with our indicator of institutional opportunity structures, our measure of the importance of institutional arenas focuses on the preparatory phase of legislation. While the preparatory phase is known as a major decision-making phase in Swiss decision-making processes, its importance nevertheless varies from one process to the other (Kriesi 1980; Sciarini 2014, 2015; Sciarini, Fischer, and Traber 2015). To assess the importance of preparatory arenas we rely on a question asking our interview partners to identify, from a predefined list, the arenas that in their view had been "very important" for the final policy output, that is, "where important decisions with respect to the policy output were taken." Table 1 shows, for each process, the aggregate share of respondents who mentioned the arenas of the preparatory phase as being "very important."

\section{RESULTS}

Table 2 presents the results of the model including all variables presented above for each of the 11 decision-making

12. Exact wording of the question: "I would like to ask you to indicate which actors were, in your view, very influential in the decision-making process $x$." 


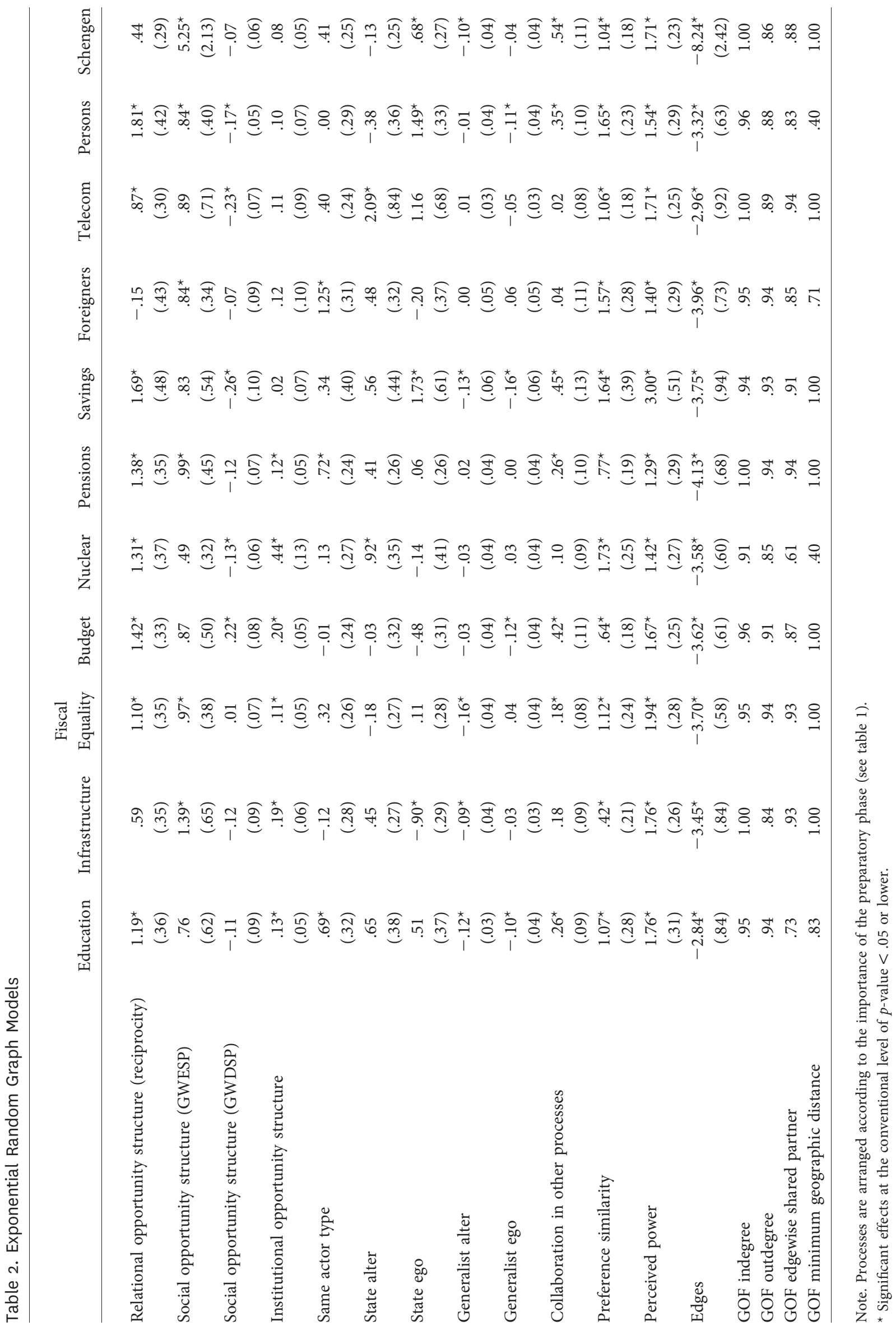


processes. ${ }^{13}$ Given that we present 11 different models, we refrain from interpreting the size of effects and focus instead on their direction and significance. The direction of the coefficients indicates increasing or decreasing probabilities of observing a collaborative tie. ${ }^{14}$ Entries marked with an asterisk point to significant effects at the conventional level of $p$-values of .05 or lower. Starting with the relational opportunity structure, the reciprocity parameter is positive in eight networks and has no effect in three. While relational opportunity structures do not prompt collaboration in all cases, the use of reciprocity as a criterion to decide whom to contact nevertheless appears as a fairly widespread strategy, one that holds in a variety of decisionmaking sectors and processes.

Results are less clear-cut with respect to social opportunity structures. The GWESP term is significant and positive in six networks but not significant in five. ${ }^{15}$ In line with earlier studies emphasizing the role of common contacts in reducing uncertainty about the worthiness of a new collaborative tie, the social opportunity structure has a positive influence on the creation of a collaborative tie in a short majority of cases. However, in almost half of the cases, shared contacts do not have the expected effects, which means that social opportunity structures do not foster collaboration in all cases.

13. As an alternative, we could aggregate the data from our 11 separate networks and estimate a pooled model. However, in order to test our hypothesis regarding differences across networks, we would need to include a high number of interactions terms. We therefore opted for separate models but nevertheless estimated a pooled model (see table A1 in the appendix). Results are in line with those of table 2 but are of course less precise. The fact that the pooled model does not capture differences between processes presumably accounts for the relatively poor model fit, which is much lower than that of the 11 networks taken separately-especially with respect to edgewise shared partners. As an additional test, we followed Cranmer and Desmarais (2012) and excluded those networks that had a higher density than others (education, telecom) or that were different from others on the basis of a multidimensional scaling representation of individual model coefficients (Schengen). This does not affect the results.

14. The size of effects, i.e. the odds ratio of observing a collaborative tie if the independent variable increases by one unit, can nonetheless be obtained by calculating the exponential function of effects, as in a logit regression model (Hunter et al. 2008). For example, in the pension reform, the probability that two actors collaborate increases by $30 \%\left(0.3\right.$, i.e., $e^{26}-$ 1) for each parallel decision-making process in which they collaborate; their probability of collaborating increases by $13 \%$ for each venue they participate in jointly. In the same network, the probability that actor $a$ collaborates with actor $b$ increases by $264 \%$ if $a$ considers $b$ as influential.

15. The significance and negative sign of the GWDSP parameters in four networks show that in these networks, unconnected dyads with shared partners are less frequent than expected in a random network. This is one indicator of triadic closure, but the related and crucial GWESP parameter is significant in only one of the four networks.
Institutional opportunity structures, as measured by joint participation in institutional arenas of the preparatory phase of political decision making, also have a significant effect in six out of 11 networks. In those six cases, the higher the number of institutional arenas such as policy committees in which two actors jointly participate, the more it is likely that they collaborate. ${ }^{16}$ In the five other networks, however, institutional opportunity structures do not have a significant influence on collaborative tie formation.

In sum, our results provide mixed support for our first hypothesis of opportunity structures as drivers of collaboration. On the one hand, our cross-sector perspective backs the finding of Leifeld and Schneider's (2012) sector-specific study that relational opportunity structures prompt collaboration and suggests that this finding has a broader validity. According to our data, in most decision-making cases, actors show a propensity to reciprocate collaboration. On the other hand, the effects of social and institutional opportunity structures are not systematic and vary across decisionmaking processes.

The mixed finding regarding institutional opportunity structures was, however, not unexpected. In fact, our second hypothesis explicitly bets on varying effects across processes. According to that hypothesis, the importance of institutional arenas in which actors meet conditions the influence of institutional opportunity structures on collaboration. Our data tend to confirm that expectation. As we can see from tables 1 and 2, joint participation in institutional arenas of the preparatory phase of decision making fosters collaboration in all six processes in which the importance of this phase is deemed high (i.e., where perceived importance is higher than average). Conversely, the institutional opportunity structure has no effect on the creation of collaborative ties in the remaining five processes in which the importance of the preparatory phase is lower than average. ${ }^{17}$

Thus, our results provide encouraging support for our hypothesis that the influence of institutional opportunity structures on collaboration is conditional on the importance of the corresponding institutional arenas. The incentive function exerted by joint participation in the preparatory phase

16. Results remain the same if we use a variable measuring joint participation relative to the number of available arenas per process instead of the absolute number of joint participations.

17. A closer look at table 2 shows that the five cases in which the preparatory phase is less important are all to some extent Europeanized (Fischer and Sciarini 2013; Sciarini 2014): the three bilateral agreements with the European Union, which were to a large extent decided "from the outside," and the foreigners law and telecom act, where domestic working groups and consultation procedures had more of a "window dressing" character. 
of legislation on the propensity to collaborate is weaker if this phase is little important than if it is highly important. In the latter case, actors can participate in codecision and coproduction of solutions, which gives rise to more intense interactions. If actors are aware that the arenas in which they meet will have an influence on the policy outputs, they invest more time and resources and are more prone to establish collaboration. ${ }^{18}$

Table 2 also highlights the strong importance of preference similarity and perceived power, which we introduced as control variables. Both variables have a significant and positive effect on collaboration in all 11 decision-making cases. This result highlights the crucial importance of these two classic predictors of collaboration. Further, while opportunity structures absorb the effect of preference similarity in Leifeld and Schneider's (2012) sector-based study, our analysis of 11 different sectors shows that opportunity structures and preference similarity are distinct and complementary drivers of collaborative tie formation. By contrast, the other control variables (formal authority, same actor type, and generalist) do hardly matter. ${ }^{19}$

Turning to our third hypothesis about the effect of collaboration between two actors in parallel decision-making processes on their collaboration in a given process, table 2 shows that this effect is significant (and positive) in seven out of the 11 networks under study. This result lends partial support to our hypothesis. ${ }^{20}$ Collaborative ties that have developed in parallel processes tend to favor mutual knowledge and trust and to increase the risk of defection. As a result, they provide actors with incentives to also collaborate in the decision-making process of interest. Even with only partial empirical support, this finding is important from a theoretical viewpoint. The fact that collaboration patterns in a policy sector are (partially) influenced by what happens in other policy sectors indicates that the usual sector focus in

18. Additional tests, not reported here, confirm that the importance of decision-making phases in which two actors meet matters. If, as a measure of institutional opportunity structures, we use the number of joint participations in the three most important arenas of the preparatory phase (instead of the number of joint participations in all arenas of the preparatory phase), we find that joint participation has a significant, positive impact on collaborative tie formation in nine cases out of 11 .

19. The edges parameter controls for the number of edges in the networks, i.e. for network density. It is negative in 10 networks, meaning that actors have a negative tendency to send random ties.

20. Including the variable measuring collaboration in other networks does not level out the effect of the classic drivers of tie formation such as power or preference similarity. This suggests that this variable further adds to the explanation of collaboration between political actors. The goodness-of-fit tests support this view, as including collaboration in other networks increases the fit of the model in more than half of the cases (six). policy studies is a limitation (Hoberg and Morawski 2008; Lubell et al. 2010). ${ }^{21}$

Against our expectations, however, interactions across sectors do not have a systematic influence on collaboration. In four cases, their effect is not significant. More work is thus needed to account for these differences in effects between processes. As a first hint we may point to the type of policy at stake (e.g., Lowi 1972). In our data the seven cases in which contacts established in other sectors influence collaboration relate to either redistributive or constitutive policies. By contrast, the four cases in which collaboration in other sectors does not have the expected effect are either regulative (telecommunication act, foreigners law, and law on nuclear energy) or distributive policies (law on infrastructure fund). In these policies, general values about how society should be organized are of little importance. Actors defending narrow interests mainly attempt to profit from a given policy output. This, in turn, might reduce their sensitivity to cross-sector influences. While this explanation is admittedly tentative, it opens a promising avenue for further research.

\section{CONCLUSION}

On the basis of an exceptionally rich set of collaboration network data covering 11 different decision-making processes and the application of exponential random graph models for network data, we contribute to the growing literature regarding the drivers of collaboration between actors in political decision-making processes. For both theoretical and practical reasons, existing studies have focused on single policy sectors. This overlooks both the likely differences in the patterns of influence between sectors and the possible influences across sectors. On both accounts, our comparative analysis across sectors makes a step forward and provides compelling, if not overwhelming, support to our hypotheses.

First, we analyze whether drivers of collaboration have a broad relevance or whether they hold in specific policy sectors only. On the one hand, our results show that preference similarity and perceived power have a far-reaching influence. In fact, they are the only two factors that matter in all 11 decision-making processes. Therefore, our Swiss

21. The results of two additional models are provided in the appendix. Model A2 excludes the collaboration across networks, whereas model A3 leaves out all types of opportunity structures. The results remain fairly stable in model A2. By contrast, in model A3 the control variables measuring the same actor type and formal authority (state actors) become significant in a high number of cases. This suggests that opportunity structures, among others, allow actors of the same type to establish collaboration, as well as collaboration to and from state actors. 
data confirm the overriding importance of preference similarity and power as drivers of collaboration. Similarly, the relational opportunity structure also has a fairly consistent influence on the creation of collaborative ties. Actors' tendency to reciprocate incoming ties and, therefore, to profit from a costless communication channel holds in most decision-making processes included in our study.

On the other hand, the role of social and institutional opportunity structures fluctuates across policy processes. While social opportunity structures tackle endogenous network effects, it will be up to future research to identify the conditions under which these effects foster collaboration. With respect to institutional opportunity structures, our analysis offers a plausible explanation for cross-sector variations. Our data tend to confirm that the effects of institutional opportunity structures vary according to the importance of the corresponding arenas. More specifically, joint participation in institutional arenas fosters collaboration only if these arenas are important for policy outputs. In the latter case the higher the number of arenas two actors take part in, the higher the likelihood of collaboration.

Second, our analysis sheds light on interactions across sectors, which also contribute to the explanation of collaborative tie formation. Collaboration experience in other processes helps actors to choose contacts that minimize transaction costs and increase the expected benefits, thanks to the development of trust and mutual dependencies. Collaboration between actors in a given decision-making process is thus more likely if these actors also collaborate in other processes. True, the effects of collaboration across sectors do not hold in all processes. However, the fact that they show up in a majority of cases in a country like Switzerland with strong sectoral differentiation and weak bargains and political exchanges across sectors suggests that they have a broader validity. Future research needs to check whether our hint regarding the mediating role of the policy type is a valid explanation for the differential impact of cross-sector collaboration.

Our results have implications for the study of political decision making and public policy more generally. First, the variations in the effects of opportunity structures across decision-making cases underscore the importance of a comparative analysis across sectors. Second, and relatedly, our results call for an analysis of how the effects of opportunity structures and other drivers of collaboration depend on process-related or policy-related characteristics. Third, our analysis provides some empirical support to the claim that actors rely on previous or parallel experiences from other policy sectors when choosing their collaboration partners. Therefore, if one wishes to understand how actors behave in a given policy sector, it seems important to also take into account what is going on outside that sector.

\section{ACKNOWLEDGMENTS}

We are grateful to Skyler Cranmer and Philip Leifeld for methodological support and comments on earlier versions of this manuscript. We also thank the five anonymous reviewers and the journal editors for their constructive feedback. Support for this research was provided by the Swiss National Science Foundation (grant 100012-113964).

\section{REFERENCES}

Baumgartner, Frank R., and Bryan D. Jones. 1991. "Agenda Dynamics and Policy Subsystems.” Journal of Politics 53 (4): 1044-74.

Berardo, Ramiro. 2009. "Generalized Trust in Multi-organizational Policy Arenas: Studying Its Emergence from a Network Perspective.” Political Research Quarterly 62 (1): 178-89.

Berardo, Ramiro. 2013. "The Coevolution of Perceptions of Procedural Fairness and Link Formation in Self-Organizing Policy Networks." Journal of Politics 75 (3): 686-700

Berardo, Ramiro, and John T. Scholz. 2010. "Self-Organizing Policy Networks: Risk, Partner Selection and Cooperation in Estuaries." American Journal of Political Science 54 (3): 632-49.

Carpenter, Daniel P., Kevin M. Esterling, and David M. Lazer. 2004. "Friends, Brokers, and Transitivity: Who Informs Whom in Washington Politics?" Journal of Politics 66 (1): 224-46.

Coleman, James S. 1988. "Social Capital in the Creation of Human Capital.” American Journal of Sociology 94 (suppl.): 95-120.

Cranmer, Skyler J., and Bruce A. Desmarais. 2011. "Inferential Network Analysis with Exponential Random Graph Models." Political Analysis 19 (1): 66-86

Desmarais, Bruce A., and Skyler Cramner. 2012. "Micro-Level Interpretation of Exponential Random Graph Models with Application to Estuary Networks." Policy Studies Journal 40 (3): 402-34.

Feiock, Richard C. 2013. "The Institutional Collective Action Framework." Policy Studies Journal 41 (3): 397-425.

Feiock, Richard C., In Won Lee, Hyung Jun Park, and Keon-Hyung Lee. 2010. "Collaboration Networks among Local Elected Officials: Information, Commitment, and Risk Aversion." Urban Affairs Review 46 (2): 241-62.

Feiock, Richard C., and John Scholz. 2010. Self-Organizing Federalism. Cambridge: Cambridge University Press.

Fischer, Manuel. 2015. "Institutions and Coalitions in Policy Processes: A Cross-Sectoral Comparison.” Journal of Public Policy 35 (2): 245-68.

Fischer, Manuel, and Pascal Sciarini. 2013. "Europeanization and the Inclusive Strategies of Executive Actors." Journal of European Public Policy 20 (10): 1482-98.

Fischer, Manuel, and Pascal Sciarini. 2015. "Unpacking Reputational Power: Intended and Unintended Determinants of the Assessment of Actors' Power." Social Networks 42:60-71.

Gerber, Elisabeth R., Adam Douglas Henry, and Mark Lubell. 2013. "Political Homophily and Collaboration in Regional Planning Networks." American Journal of Political Science 57 (3): 598-610.

Gilardi, Fabrizio. 2010. "Who Learns from What in Policy Diffusion Processes?" American Journal of Political Science 54 (3): 650-66.

Granovetter, Mark. 1985. "Economic Action and Social Structure: The Problem of Embeddedness." American Journal of Sociology 91 (3): 481510 . 
Heaney, Michael. 2014. "Multiplex Networks and Interest Group Influence Reputation: An Exponential Random Graph Model.” Social Networks 36:66-81.

Henry, Adam Douglas. 2011. "Ideology, Power, and the Structure of Policy Networks.” Policy Studies Journal 39 (3): 361-83.

Hoberg, George, and Edward Morawski. 2008. "Policy Change through Sector Intersection: Forest and Aboriginal Policy in Clayoquot Sound." Canadian Public Administration 40 (3): 387-414.

Hunter, David R. 2007. "Curved Exponential Family Models for Social Networks.” Social Networks 29 (2): 216-30.

Hunter, David R., Steven M. Goodreau, and Mark S. Handcock. 2008. "Goodness of Fit of Social Network Models." Journal of the American Statistical Association 103 (481): 248-58.

Hunter, David R., Mark S. Handcock, Carter T. Butts, Steven M. Goodreau, and Martina Morris. 2008. "ergm: A Package to Fit, Simulate and Diagnose Exponential-Family Models for Networks." Journal of Statistical Software 24 (3): 1-29.

Ingold, Karin, and Manuel Fischer. 2014. "Drivers of Collaboration to Mitigate Climate Change: An Illustration of Swiss Climate Policy over 15 Years." Global Environmental Change 24:88-98.

Jenkins-Smith, Hank C., Daniel Nohrstedt, Christopher M. Weible, and Paul A. Sabatier. 2014. "The Advocacy Coalition Framework: Foundations, Evolution, and Ongoing Research." In Christopher M. Weible and Paul A. Sabatier, eds., Theories of the Policy Process. Boulder, CO: Westview, 183-224.

Jones, Michael D., and Hank C. Jenkins-Smith. 2009. “Trans-subsystem Dynamics: Policy Topography, Mass Opinion, and Policy Change.” Policy Studies Journal 37 (1): 37-58.

Klijn, Erik-Hans, Bram Steijn, and Jurian Edelenbos. 2010. "The Impact of Network Management on Outcomes in Governance Networks.” Public Administration 88 (4): 1063-82.

Knoke, David. 1993. "Networks of Elite Structure and Decision Making." Sociological Methods and Research 22 (1): 22-45.

König, Thomas, and Thomas Bräuninger. 1998. “The Formation of Policy Networks: Preferences, Institutions and Actors' Choice of Information and Exchange Relations." Journal of Theoretical Politics 10 (4): 445-71.

Koontz, Tomas M., and Elizabeth Moore Johnson. 2004. “One Size Does Not Fit All: Matching Breadth of Stakeholder Participation to Watershed Group Accomplishments." Policy Sciences 37 (2): 185-204.

Kriesi, Hanspeter. 1980. Entscheidungsstrukturen und Entscheidungsprozesse in der Schweizer Politik. Frankfurt: Campus Verlag.

Laumann, Edward O., and Franz Urban Pappi. 1973. "New Directions in the Study of Community Elites." American Sociological Review 38: 212-30.

Leifeld, Philip, and Volker Schneider. 2012. "Information Exchange in Policy Networks." American Journal of Political Science 53 (3): 731-44.

Lowi, Theodore J. 1972. "Four Systems of Policy, Politics and Choice." Public Administration Review 32 (4): 298-310.

Lubell, Mark. 2004. "Collaborative Environmental Institutions: All Talk and No Action?” Journal of Policy Analysis and Management 23 (3): 549-73.

Lubell, Mark. 2007. "Familiarity Breeds Trust: Collective Action in a Policy Domain.” Journal of Politics 69:237-50.

Lubell, Mark, Adam D. Henry, and Mike McCoy. 2010. "Collaborative Institutions in an Ecology of Games." American Journal of Political Science 54 (2): 287-300.

Lubell, Mark, Mark Schneider, John T. Scholz, and Mihriye Mete. 2002. "Watershed Partnerships and the Emergence of Collective Action Institutions." American Journal of Political Science 46 (1): 148-63.

Lubell, Mark, John Scholz, Ramiro Berardo, and Garry Robins. 2012. "Testing Policy Theory with Statistical Models of Networks." Policy Studies Journal 40 (3): 351-74.
Morris, Martina, Mark S. Handcock, and David R. Hunter. 2008. "Specification of Exponential-Family Random Graph Models: Terms and Computational Aspects.” Journal of Statistical Software 24 (4): 1-24.

North, Douglass C. 1990. “A Transaction Cost Theory of Politics." Journal of Theoretical Politics 2 (4): 355-67.

Putnam, Robert D. 1995. "Bowling Alone: America's Declining Social Capital.” Journal of Democracy 6 (1): 65-78.

Robins, Garry, Pip Pattison, Yuval Kalish, and Dean Lusher. 2007. “An Introduction to Exponential Random Graph $\left(p^{\star}\right)$ Models for Social Networks." Social Networks 29:173-91.

Sabatier, Paul A. 1987. "Knowledge, Policy-Oriented Learning, and Policy Change: An Advocacy Coalition Framework." Science Communication 8:649-92.

Sabatier, Paul A., and Christopher M. Weible. 2007. "The Advocacy Coalition Framework." In Paul A. Sabatier, ed., Theories of the Policy Process. Boulder, CO: Westview, 189-222.

Schneider, Mark, John Scholz, Mark Lubell, Denisa Mindruta, and Matthew Edwardsen. 2003. "Building Consensual Institutions: Networks and the National Estuary Program.” American Journal of Political Science 47 (1): 143-58.

Scholz, John T., Ramiro Berardo, and Brad Kile. 2008. "Do Networks Solve Collective Action Problems? Credibility, Search, and Collaboration." Journal of Politics 70 (2): 393-406.

Sciarini, Pascal. 2014. "Eppure si Muove: The Changing Nature of the Swiss Consensus Democracy.” Journal of European Public Policy 21 (1): 116-32.

Sciarini, Pascal. 2015. "From Corporatism to Bureaucratic and Partisan Politics: Changes in Decision-Making Processes over Time.” In Pascal Sciarini, Manuel Fischer, and Denise Traber, eds., Political DecisionMaking in Switzerland: The Consensus Model under Pressure. Basingstoke, UK: Palgrave Macmillan, 24-50.

Sciarini, Pascal, Manuel Fischer, and Denise Traber, eds. 2015. Political Decision-Making in Switzerland: The Consensus Model under Pressure. Basingstoke, UK: Palgrave Macmillan.

Shrestha, Manoj K., Ramiro Berardo, and Richard C. Feiock. 2014. "Solving Institutional Collective Action Problems in Multiplex Networks." Complexity, Governance and Networks 1 (1): 49-60.

Shrestha, Manoj K., and Richard C. Feiock. 2009. "Governing U.S. Metropolitan Areas: Self-Organizing and Multiplex Service Networks." American Politics Research 37 (5): 801-23.

Shrestha, Manoj K., and Richard C. Feiock. 2011. "Transaction Cost, Exchange Embeddedness, and Interlocal Cooperation in Local Public Goods Supply." Political Research Quarterly 64 (3): 573-87.

Stokman, Frans N., and Evelien P. H. Zeggelink. 1996. "Is Politics Power or Policy Oriented? A Comparative Analysis of Dynamic Access Models in Policy Networks." Journal of Mathematical Sociology 21 (1-2): 77-111.

Verweij, Stefan, Erik-Hans Klijn, Jurian Edelenbos, and Arwin Van Buuren. 2013. "What Makes Governance Networks Work? A Fuzzy Set Qualitative Comparative Analysis of 14 Dutch Spatial Planning Projects.” Public Administration 91 (4): 1035-55.

Weible, Christopher M. 2005. "Beliefs and Perceived Influence in a Natural Resource Conflict: An Advocacy Coalition Approach to Policy Networks." Political Research Quarterly 58 (3): 461-75.

Weible, Christopher M., and Paul A. Sabatier. 2005. "Comparing Policy Networks: Marine Protected Areas in California.” Policy Studies Journal 33 (2): 181-201.

Williamson, Oliver E. 1991. "Comparative Economic Organization: The Analysis of Discrete Structural Alternatives.” Administrative Science Quarterly 36 (2): 269-96.

Zafonte, Matthew, and Paul Sabatier. 1998. "Shared Beliefs and Imposed Interdependencies as Determinants of Ally Networks in Overlapping Subsystems." Journal of Theoretical Politics 10 (4): 473-505. 